\title{
Mechanical and Tribological Properties of Ti-Containing Carbon Nanocomposite Coatings Deposited on TiAlV Alloys
}

\author{
Emanuel Santos Júnior ${ }^{\mathrm{a},}$, Sérgio de Souza Camargo Júnior ${ }^{\mathrm{a}}$, \\ Glória de Almeida Soares ${ }^{\mathrm{a}}$,Marie-Paule Delplancke-Ogletree ${ }^{\mathrm{b}}$ \\ ${ }^{a}$ Department of Metallurgical and Materials Engineering, COPPE, \\ Federal University of Rio de Janeiro, CP 68505, CEP 21941-972, Rio de Janeiro, RJ, Brazil \\ ${ }^{\mathrm{b}}$ Chemicals and Materials Department, Faculty of Applied Science, \\ Université Libre de Bruxelles, Avenue F.D. Roosevelt 50, 1050, CP 165/63, Brussels, Belgium
}

Received: September 1, 2010; Revised: December 3, 2010

\begin{abstract}
Ti-doped carbon coatings were deposited on TiAlV alloys by reactive dc-magnetron sputtering in $\mathrm{Ar} / \mathrm{CH}_{4}$ mixed gas. When Ar flow increases the incorporation of Ti into films raises while the concentration of $\mathrm{C}$ decreases. The formed nanometric TiC crystals were more noticeable for coatings deposited with higher Ar flows. Hardness $(H)$ and elastic modulus $(E)$ of coatings were measured by nanoindentation. $H$ values were in the range of 8.8-15.9 GPa and $E$ of 53.4-113.7 GPa. Higher values for $H$ and $E$ were obtained for films containing larger amount of TiC-phase. The presence of TiC crystals increased the coefficient of friction (COF) from 0.07 to 0.28 in scratch tests. Tribological experiments were carried out by using a pin-on-disk apparatus in air and in liquid. COF values ranged from 0.10 to 0.50 for tests in air. Despite of presenting higher COF, tests performed in liquid resulted in less pronounced wear tracks.
\end{abstract}

Keywords: carbon-based coatings, depth-sensing nanoindentation, mechanical properties, tribology, wear

\section{Introduction}

Carbon-based films have been studied since 1971, when Aisenberg and Chabot $^{1}$ produced diamond-like carbon thin films by ion-beam deposition technique. The amorphous structure may lead to coatings with a wide range of properties, once these materials can present the main characteristics of both diamond and graphitic carbons. Hardness is generally linked to a $\mathrm{C} s p^{3}$-hybridized network that surrounds small $\mathrm{C} s p^{2}$-hybridized islands in amorphous-carbon. In fact, the properties of carbon-based films are mostly influenced by the content and how $\mathrm{C} s p^{2}$ and $s p^{3}$ hybridizations are arranged, as well as the amount of $\mathrm{H}$ into amorphous-carbon matrix ${ }^{2}$. Additionally, some foreign elements (for example, $\mathrm{Ti}, \mathrm{Si}, \mathrm{O}$ and $\mathrm{F}$ ) are frequently incorporated into the amorphous matrix in order to tailor the properties of the coatings ${ }^{2-4}$. Hence a considerable variety of carbon-based films can be produced as far as the nano/micro-structure, chemical composition, optical, mechanical and tribological properties are concerned. These films are usually prepared by several deposition techniques, such as ion deposition, ion assisted sputtering, cathodic vacuum arc, sputtering, plasma deposition and pulsed laser deposition ${ }^{2}$.

Nanocomposite coatings can be formed by small crystallites embedded in an amorphous matrix ${ }^{5}$. In general, hard crystallites (for instance, carbides, oxides and nitrides) dispersed into a softer matrix material can reduce the compound hardness and elastic modulus, but the nanocomposite coating becomes tougher ${ }^{6-8}$. Therefore the presence of these crystals as a second phase is an important parameter that must be taken into account for predicting the properties of nanocomposite coatings. For example, hard titanium carbide (TiC) crystals embedded into a-C:H matrix can improve the wear resistance of coatings ${ }^{8,9}$. The small TiC crystals are, to a certain extent, responsible for the good fracture toughness of nanocomposite coatings, while the soft carbon-based matrix accounts for the self-lubrication properties 9 . TiC-containing carbon composite films have been widely studied by several authors for many different purposes ${ }^{6,10-12}$.
Nowadays carbon-based coatings attract interest for applications as protective coatings in many areas, such as magnetic storage disks, sliding bearings, gears, manufacturing tools, polyethylene terephthalate (PET) bottles, in textile and biomedical industries ${ }^{13-15}$. They can present low coefficient of friction ${ }^{13}$ and reduced wear rate, being good candidates for tribological applications.

The interposition of wear debris between the femoral head and socket (counter-part) of total hip prostheses (THP) is one of the main factors for implants failures, as reported by many orthopaedic surgeons $\mathrm{s}^{16}$. They often provoke bone-resorption (osteolysis), undesirable tissue reactions, and then aseptic loosening of $\mathrm{THP}^{16}$. A number of devices for bio-tribology studies have been employed to evaluate the wear and frictional properties of candidate materials to THP. The most common used apparatuses are pin (ball)-on-disk and pin (ball)-on-flat, which allow to control the applied normal force, angular velocity, and lubrication medium as well ${ }^{17-19}$. The development and use of more sophisticated equipments with multi-directional movements provide a better mimicking of both natural knees and hip joints ${ }^{20-22}$. Notwithstanding, cheaper and easier systems, like ballon-disk apparatus, can be satisfactorily used as a first evaluation of wear on different materials. Several lubricants are usually applied for tribological tests in liquid, for instance: water $^{23}$, Ringer's and $\mathrm{NaCl}$ solutions $^{24}$, natural synovial fluid ${ }^{25}$, bovine and caprine fetal serum ${ }^{19,25}$. Results from wear tests carried out in joint simulators, using bovine or caprine serum solution as lubricant medium, showed better agreement with clinical uses with respect to the wear volume of THP ${ }^{25}$.

This work concerns the mechanical and tribological properties of Ti-doped carbon nanocomposite films. Coatings were deposited on TiAlV alloy by reactive dc-magnetron sputtering under different conditions. Nanoindentation was the main technique used to mechanical characterisations. The tribo-indenter was also used to perform scratch tests. Wear tests were carried out in air and in liquid using a pin-on-disk tribometer. 


\section{Materials and Methods}

Carbon-based films were deposited on commercial TiAlV alloy substrates with dimensions of $20 \times 20 \times 1.5 \mathrm{~mm}^{3}$. Substrates were mechanically abraded with $\operatorname{SiC}$ paper $(400,600,800$ and 1200 grits), and then polished by using a colloidal silica suspension (Struers $\mathrm{A} / \mathrm{S}$ ) in order to obtain mirror-like surfaces. Reactive dc-magnetron sputtering was the technique used for deposition from a pure Ti target with a power density of $1.7 \mathrm{~W} \cdot \mathrm{cm}^{-2}$. A mixture of gases $\mathrm{Ar}+\mathrm{CH}_{4}$ was employed with different $\left(\mathrm{Ar} / \mathrm{CH}_{4}\right)$ gas flows: 170/50, 190/30, and $210 / 10 \mathrm{sccm}$, maintaining the total flow at $220 \mathrm{sccm}$. All coatings were deposited with a constant applied substrate bias voltage of $-300 \mathrm{~V}$. Titanium inter-layers were deposited to improve the film adhesion on the metallic substrates. For each condition, the deposition time was previously calculated to obtain films $200-300 \mathrm{~nm}$ thick.

The concentrations of $\mathrm{C}, \mathrm{Ti}$ and $\mathrm{O}$ in the deposited films were estimated by Auger spectroscopy with an equipment from Physical Electronics model PHI. Samples were previously sputtered with Ar ions of $2 \mathrm{keV}$ for 70 minutes to remove surface contamination. Then measurements were performed with an electron beam of $3 \mathrm{keV}$ and 5 scans for energies in the range 30-600 eV. Concentrations were calculated by using the table of sensitivity factor of elements ${ }^{26}$. Grazing angle X-ray diffraction (XRD) was performed with a Bruker D500 difractometer with $\mathrm{Cu} \mathrm{K} \alpha$ radiation $(\lambda=1.5106 \AA)$ and an incident angle $(\theta)$ of $1^{\circ}$. XRD peaks were identified by using the JCPDS cards n ${ }^{\circ} 01-1198$ (Ti), 32-1383 (TiC), and 86-2352 (TiO). The sizes of TiC crystallites were estimated from the Scherrer's formula ${ }^{27}$.

Mechanical properties, namely hardness and elastic modulus, were measured by nanoindentation technique with a Hysitron tribo-indenter. A diamond Berkovich-type tip was employed for indentations. Fused silica with known properties was used for calibration, and Poisson's coefficient of 0.25 was applied to calculations ${ }^{28}$. A total of 80 indents were performed on each sample under loads from 0.5 up to $5.0 \mathrm{mN}$. Values for hardness and elastic modulus shown herein were obtained using the Oliver \& Pharr $\operatorname{method}^{29}$ for the load of $2.55 \mathrm{mN}$. Also elastic recovery $(E R)$ parameter was calculated for each indentation test by applying the ratio $\left(h_{\max }-h_{\mathrm{f}}\right) / h_{\max }$, where $h_{\max }$ is the maximum penetration depth (during loading) and $h_{\mathrm{f}}$ is the final depth penetration (after unloading).

Scratch tests were performed with a Berkovich tip with a maximum applied normal load of $5.0 \mathrm{mN}$. A total number of 5 scratches (500 $\mathrm{nm}$ in length) were performed on each sample at a loading rate of $0.5 \mathrm{mN} / \mathrm{s}$. Figure 1 shows the load and displacement functions applied to the tip. First, the tip was shifted to the initial position, and from this point it travelled $500 \mathrm{~nm}$ under a normal load of $0.3 \mathrm{mN}$ in order to obtain the pre-scans (or original surfaces) profiles. Then, the tip was kept loaded under $0.3 \mathrm{mN}$ for $3 \mathrm{sec}$ at this point, and displaced backwards under rising loads from 0.3 up to $5.0 \mathrm{mN}$ for 10 seconds. After that, the tip was unloaded to $0.3 \mathrm{mN}$ during 3 seconds. Finally, the post-scans profiles were collected by displacing the tip towards the final position $(500 \mathrm{~nm})$ under the load of $0.3 \mathrm{mN}$.

The coefficient of friction (COF) was determined by measuring the lateral force $(L)$ during scratching and obtaining the $L / N$ ratio, where $N$ is the applied normal load. Comparisons between preand post-scans profiles allowed calculating the elastic recovery for the applied normal loads of 0.5, 1.0, 2.5 and $4.5 \mathrm{mN}$. For each sample, values were calculated by applying the equation previously mentioned for $E R$, and thus the average values were obtained from the 5 scratches.

Wear experiments were carried out by using a pin-on-disk tribometer (CSM/Switzerland) in two different media: in air and in bovine serum. An AISI420 steel ball of $6.0 \mathrm{~mm}$ in diameter was used as counter-part. An applied normal force of $1.0 \mathrm{~N}$, tangential speed of $0.07 \mathrm{~m} / \mathrm{s}$ and 50,000 cycles were employed. All experiments were performed at room temperature (RT) and relative humidity of 50-60\%. A bovine serum solution with protein concentration of $20 \mathrm{mg} \cdot \mathrm{mL}^{-1}$ was employed as lubricant for tests in liquid medium ${ }^{22}$. A peristaltic pump was used to circulation of liquid during the tests, with a syringe carefully connected to the experimental setup to drop the liquid on the samples. Wear was qualitatively evaluated by optical microscopy by observing the tracks formed on the coatings.

The maximum hertzian contact pressure $\left(p_{\max }\right)$ for sphericalspherical paired surfaces is ${ }^{30}$ :

$$
p_{\max }=\frac{3}{2} \frac{P}{\pi \cdot a^{2}}
$$

where $P$ is the normal applied force, and $a$ follows the relation given by ${ }^{30}$ :

$$
a=\left[\frac{3}{4} \frac{P \cdot R}{E^{*}}\right]^{\frac{1}{3}}
$$

In our case, e.g. spherical-flat paired surfaces, $R$ is the sphere radius and $E^{*}$ represents the compound elastic modulus:

$$
\frac{1}{E^{*}}=\frac{\left(1-v_{1}\right)}{E_{1}}+\frac{\left(1-v_{2}\right)}{E_{2}}
$$

where $E_{1}$ and $E_{2}$ are the elastic moduli, $v_{1}$ and $\nu_{2}$ are the Poisson's coefficients of the sliding surfaces ${ }^{30}$. From Equation 1 the calculated $p_{\max }$ is around $500 \mathrm{MPa}$ for our experiments, whereas it is approximately $60 \mathrm{MPa}$ for a metal-metal paired orthopaedic prosthesis. Data from Jin et al. ${ }^{18}$ were taken in the calculations. Thus, one can conclude that the tribological conditions applied here are more severe than for clinical use.

\section{Results and Discussion}

Figure 2 shows the estimated concentrations of $\mathrm{C}, \mathrm{Ti}$ and $\mathrm{O}$ obtained from Auger spectroscopy for the produced Ti-doped carbon coatings. Carbon concentration decreased while Ti increased when $\mathrm{CH}_{4}$ flow was reduced from 50 to $10 \mathrm{sccm}$. As the $\mathrm{CH}_{4}$ flow is decreased, argon flow increases leading to a higher sputtering rate of the target and therefore incorporating a larger amount of $\mathrm{Ti}$ in the forming carbon-based film. For instance, as the Ar mass flow into the chamber increased from 170 to $210 \mathrm{sccm}$, the Ti concentration grew about 5-fold in the deposited film. All coatings presented some concentration of oxygen, which may originate from contamination during deposition or post-deposition oxidation.

XRD results for the deposited carbon-based coatings and TiAlV substrate are shown in Figure 3. In general, the incorporation of $\mathrm{Ti}$ was responsible for formation of titanium carbide (TiC) crystallites embedded in the amorphous carbon matrix. The presence of $\mathrm{TiC}$ peaks is more noticeable for coatings deposited with higher Ar mass flows (210 sccm, for example), which have higher concentration of Ti (Figure 2). The formed TiC-phase has polycrystalline structure with main peaks $\mathrm{TiC}(111)$ at $35.9^{\circ}, \mathrm{TiC}(200)$ at $41.7^{\circ}$, and $\mathrm{TiC}(220)$ at $60.4^{\circ}$. The growth of the peak intensity is related to the increase of the amount of $\mathrm{TiC}$ crystals in the amorphous matrix. Additionally, films prepared with $\left(\mathrm{Ar} / \mathrm{CH}_{4}\right)$ flows of $190 / 30 \mathrm{sccm}$ presented a peak around $64.0^{\circ}$, which corresponds to pure titanium. Calculations from Scherrer's formula showed that the TiC crystallites have nanometric sizes ranging from 2.0 to $6.0 \mathrm{~nm}$, with increasing size for higher Ti concentrations. On the other hand, TiC peaks were not clearly observed for films produced at higher $\mathrm{CH}_{4}$ mass flow $(50 \mathrm{sccm})$, which presented low Ti concentration (Figure 2). The amount of TiC-phase in the carbon matrix thus seems to grow when $\mathrm{C}(\mathrm{Ti})$ concentration 


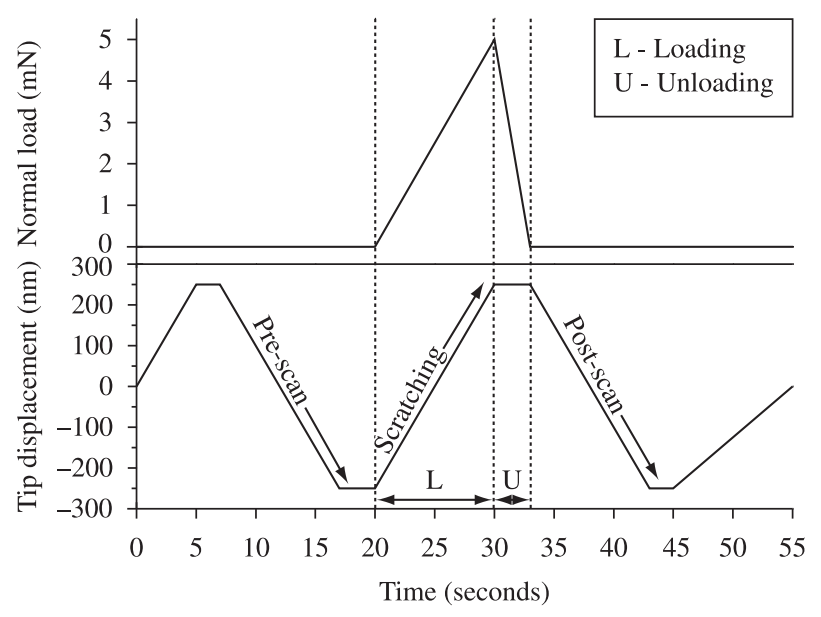

Figure 1. Loading-displacement functions applied to Berkovich tip for scratch tests on the deposited Ti-doped carbon coatings.

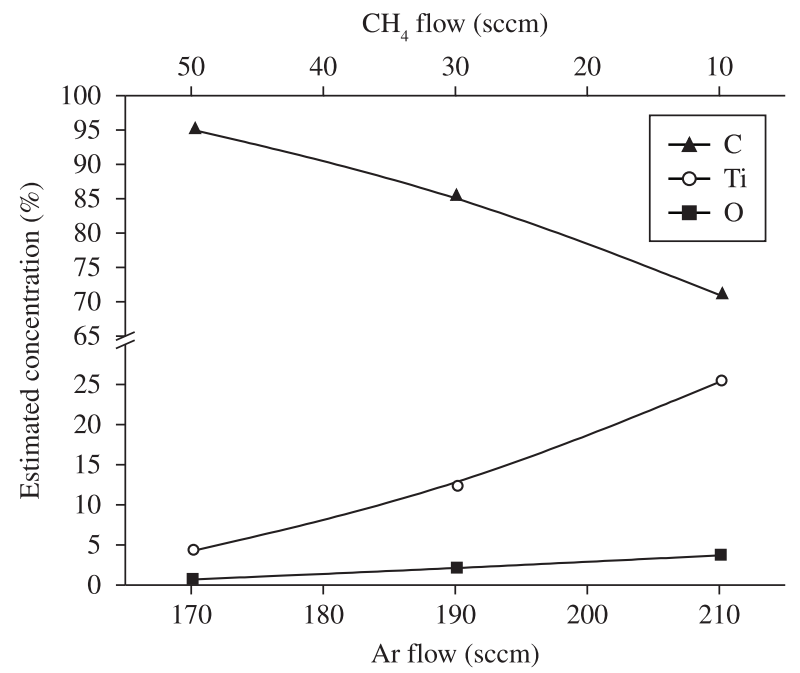

Figure 2. Concentrations of $\mathrm{C}, \mathrm{Ti}$ and $\mathrm{O}$ estimated from Auger spectroscopy for Ti-doped carbon coatings deposited with different $\mathrm{Ar}$ and $\mathrm{CH}_{4}$ flows. The total mass flow is $220 \mathrm{sccm}$. Lines are guides to the eyes.

is reduced (increased). It is worth mentioning that XRD peaks for $\mathrm{Ti}_{\mathrm{x}-1} \mathrm{O}_{\mathrm{x}}$ are positioned very close to the peaks for TiC. Therefore, the contribution of $\mathrm{TiO}$ phases in the carbon matrix for the observed XRD results cannot be ruled out. Furthermore, the assessment by the Scherrer's formula is mostlly an estimation, once the broadening of the XRD peaks is usually under influence of the instrumental- and specimen-related effects, such as the variability in shape and size of the crystallites.

Hardness $(H)$ and elastic modulus $(E)$ of the coatings were measured by instrumented indentation at nano-scale. Table 1 displays the $H$ and $E$ values measured for a normal load of $2.55 \mathrm{mN}$, which allowed to maximum contact depths in the range of $43-67 \mathrm{~nm}$. Both measured values for $H(\sim 4 \mathrm{GPa})$ and $E(\sim 120 \mathrm{GPa})$ of the polished TiAlV substrate are in good accordance to the literature ${ }^{31}$. The deposited nanocomposite films present compound hardness ranged from 9 up to $16 \mathrm{GPa}$. Hardness increases when $\mathrm{CH}_{4}$ flow in the gaseous mixture decreases. In fact, the films containing higher (lower) concentration of $\mathrm{Ti}(\mathrm{C})$ are the hardest ones.

Based on the XRD results (Figure 3 ) and the measured hardness, the greater presence of TiC-phase in the carbon matrix led to deposit

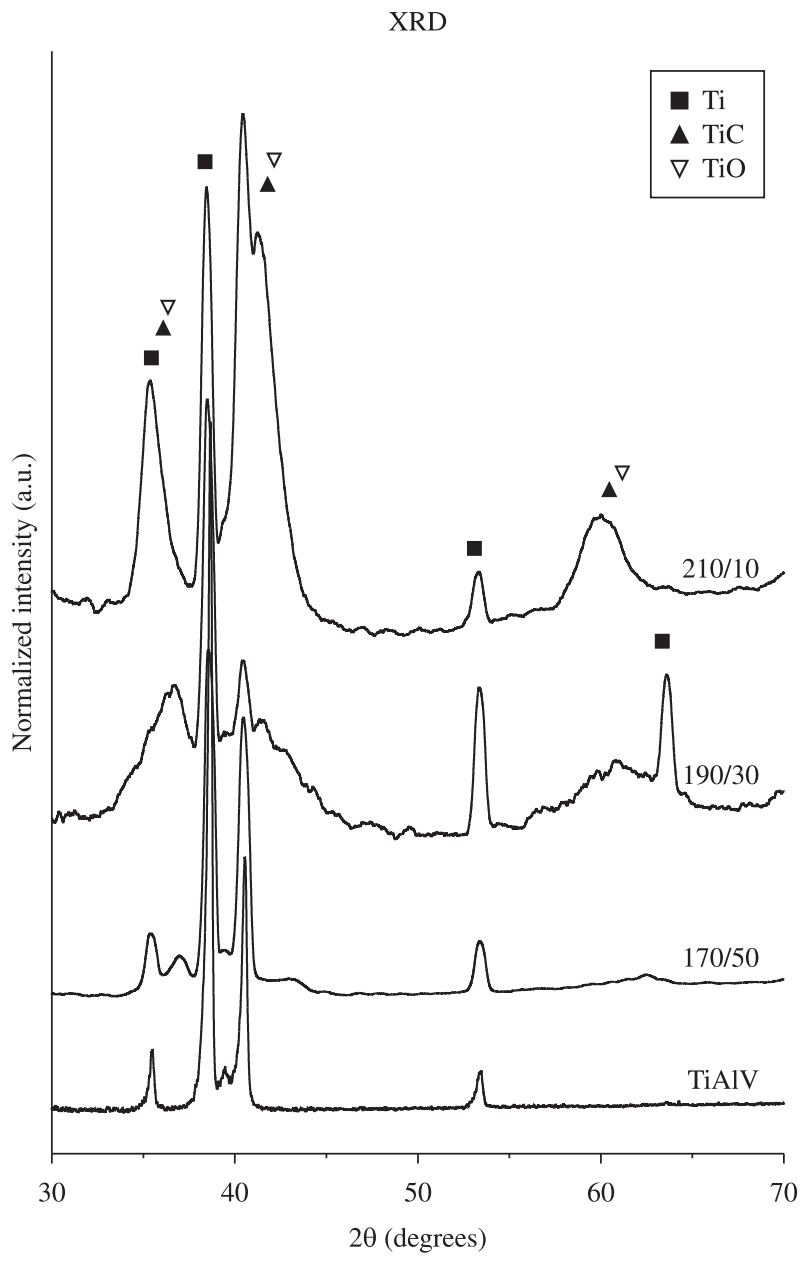

Figure 3. Grazing angle XRD results for TiAlV substrate and Ti-doped carbon coatings deposited with different $\left(\mathrm{Ar} / \mathrm{CH}_{4}\right)$ flows (in sccm). Incident $\mathrm{X}$-ray angle of $1^{\circ}$.

Table 1. Contact depth $(h)$, hardness $(H)$, elastic modulus $(E)$, and elastic recovery $(E R)$ of produced Ti-doped carbon films measured by nanoindentation for a load $\sim 2.55 \mathrm{mN}$ (mean value \pm standard deviation)*

\begin{tabular}{ccccc}
\hline $\begin{array}{c}\mathrm{Ar} / \mathrm{CH}_{4} \\
(\mathrm{sccm})\end{array}$ & $\begin{array}{c}h_{c} \pm \mathrm{SD} \\
(\mathrm{nm})\end{array}$ & $\begin{array}{c}H \pm \mathrm{SD} \\
(\mathrm{GPa})\end{array}$ & $\begin{array}{c}E \pm \mathrm{SD} \\
(\mathrm{GPa})\end{array}$ & $\begin{array}{c}E R \pm \mathrm{SD} \\
(\%)\end{array}$ \\
\hline $170 / 50$ & $67.0 \pm 3.8$ & $8.8 \pm 0.7$ & $53.4 \pm 9.6$ & $87.4 \pm 0.5$ \\
$190 / 30$ & $53.0 \pm 1.5$ & $12.1 \pm 0.5$ & $113.7 \pm 2.5$ & $85.2 \pm 1.5$ \\
$210 / 10$ & $43.4 \pm 3.5$ & $15.9 \pm 1.6$ & $113.6 \pm 19.5$ & $82.7 \pm 4.0$ \\
\hline$* \mathrm{n}=16$.
\end{tabular}

$* \mathrm{n}=16$.

harder films. When the carbon concentration increases in comparison to titanium (Figure 2), TiC crystals decrease in size, as determined from the Scherrer's formula calculation. Moreover the TiC crystallites separation enlarges in the amorphous carbon matrix ${ }^{11}$. Then the amorphous carbon-phase can dominate the mechanical behaviour ${ }^{9}$, decreasing the hardness of TiC-containing carbon nanocomposite films.

Of course, in our case, other parameters can act simultaneously on the compound hardness, such as hydrogen content in the amorphous carbon matrix. Hydrogen can saturate the $\mathrm{C}=\mathrm{C}$ bonds in the amorphous $\mathrm{C}: \mathrm{H}$ matrix, increasing the $\mathrm{C} s p^{3}$ content $^{2}$ and therefore affecting the hardness of the coating. On the other hand, the formation of TiC grains can lead to an increasing of $s p^{2}$ sites into amorphous carbon matrix ${ }^{32}$. 
Concerning the elastic modulus, the films produced with $\left(\mathrm{Ar} / \mathrm{CH}_{4}\right)$ mass flow of $170 / 50 \mathrm{sccm}$ have the lowest value. For the films deposited in higher Ar flows, it was not found significant differences between the values, as shown in Table 1. As mentioned for hardness, the larger presence of TiC crystals again increased the elastic modulus.

Besides to hardness and elastic modulus properties, the elastic recovery $(E R)$ is another interesting parameter that might predict, to a certain extent, the wear resistance of materials. It is worth noting that when $\mathrm{Ti}$ increases the $E R$ decreases slightly (Table 1), reaching values as low as $82 \%$. In fact, carbon-based films can have high $E R$ values, as those previously reported by Chowdhury and colleagues ${ }^{33}$. For tough films, Voevodin and co-workers ${ }^{6,7}$ have reported that a good value for $E R$ would be $60 \%$.

Nanoindenter is not only a versatile equipment for measuring $H$ and $E$ of materials, but also for tribological experiments at smaller scales. This is especially attractive for thin films, where the influence of substrate on the measurements must be avoided. The coefficient of friction (COF) and penetration depths during scratch tests using the nanoindenter are shown in Figure 4. Results correspond to the average value for $\mathrm{COF}$ (and penetration depth) calculated from 5 tests at different scratch lengths (and normal loads). For all samples, the COF increases when both normal load and penetration depth increase. COF values could be as low as 0.07 for shallow depths and increase up to $\sim 0.27$ at higher loads $(4.5 \mathrm{mN})$.

The COF values increase as the methane flow is reduced which corresponds to higher concentration of $\mathrm{Ti}$ into carbon films, that is, the presence of TiC crystallites into carbon matrix increased the $\mathrm{COF}$ values. These $\mathrm{TiC}$ crystals are usually covered by a-C:H layers in the amorphous carbon matrix, which is responsible for the self-lubrication, and consequently, influence the COF of carbon-based films ${ }^{9}$. Then coatings containing lower TiC/a-C:H rate should present lower COF, as seen in Figure 4. Films prepared in $\mathrm{Ar} / \mathrm{CH}_{4}$ $(210 / 10 \mathrm{sccm})$, which probably have larger amount of embedded $\mathrm{TiC}$

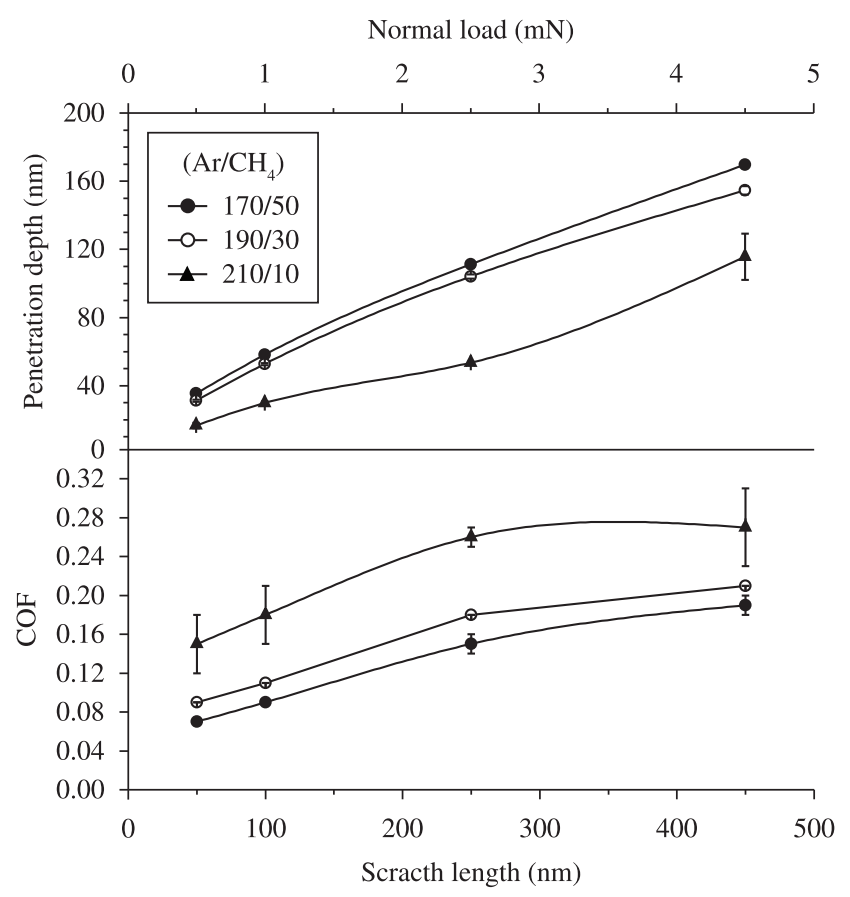

Figure 4. Variation of coefficient of friction (COF) and penetration depth of the Ti-doped carbon films submitted to scratch tests under rising loads up to $5 \mathrm{mN}$. Coatings were prepared with different $\left(\mathrm{Ar} / \mathrm{CH}_{4}\right)$ mass flows (in $\mathrm{sccm}$ ). A total of 5 scratches were performed on each sample. Lines are guides to the eyes. crystals (see Figure 3), have the shallowest penetration depths for all loads, which is related to the fact that these films are the hardest ones among those produced here (Table 1). These coatings are therefore more resistant to scratches (under low normal loads) compared to those produced with lower argon flows.

Results for elastic recovery $(E R)$ of coatings after scratching tests are shown in Table 2. The values for ER correspond to the selected normal loads of $0.5,1.0,2.5$, and $4.5 \mathrm{mN}$. As previously mentioned for indentation tests, all deposited coatings had high values for $E R$

Table 2. Elastic recovery $(E R)$ of produced carbon coatings obtained from scratch tests for different normal loads (mean value \pm standard deviation)*

\begin{tabular}{llccc}
\hline \multirow{2}{*}{$\begin{array}{c}\mathrm{Ar} / \mathrm{CH}_{4} \\
(\mathrm{sccm})\end{array}$} & $0.5 \mathrm{mN}$ & $1.0 \mathrm{mN}$ & $2.5 \mathrm{mN}$ & $4.5 \mathrm{mN}$ \\
\cline { 2 - 5 } $170 / 50$ & $94 \pm 3$ & $90 \pm 1$ & $85 \pm 1$ & $84 \pm 2$ \\
$190 / 30$ & $85 \pm 5$ & $81 \pm 2$ & $81 \pm 1$ & $83 \pm 1$ \\
$210 / 10$ & $89 \pm 11$ & $76 \pm 4$ & $75 \pm 5$ & $93 \pm 5$ \\
\hline *n $=5$. & & &
\end{tabular}

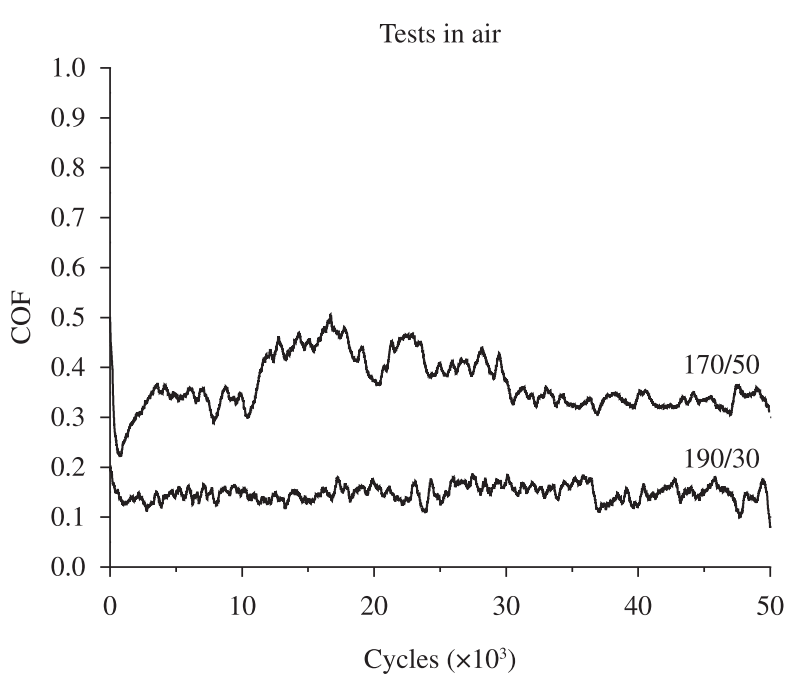

(a)

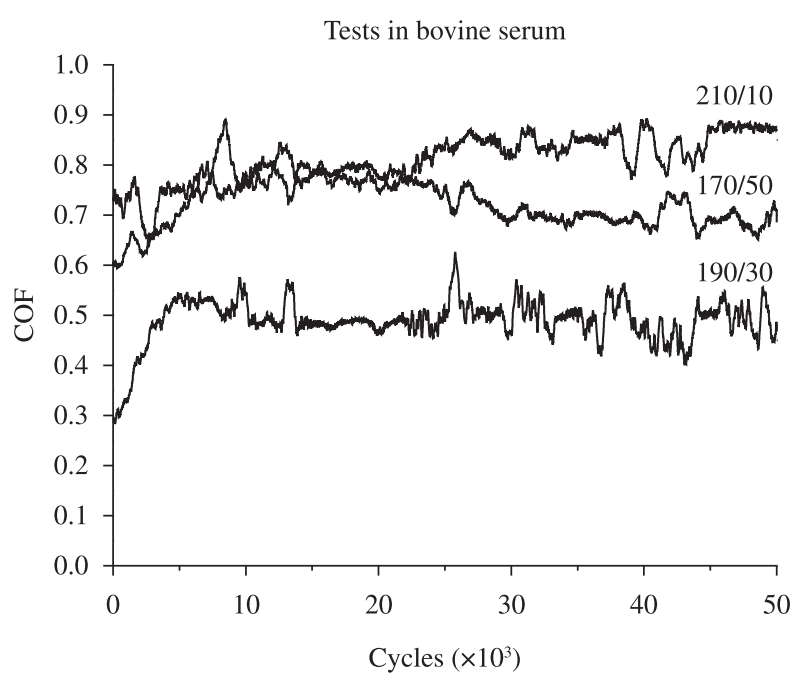

(b)

Figure 5. Variation of coefficient of friction (COF) of produced coatings from wear tests carried out by using pin-on-disk apparatus (a) in air; and (b) in liquid. Coatings deposited with different $\mathrm{Ar} / \mathrm{CH}_{4}$ flows (in sccm). 
(75 - 94\%) obtained from scratch tests. In general, the ER seemed again to decrease when the presence of TiC-phase in the coatings was increased. Due to the high elastic recovering of the carbon nanocomposite coatings, it was not possible to observe the scratches, even at higher loads (or depths).

Figure 5 shows the COF of the coatings for tribological tests carried out by pin-on-disk apparatus in air and in liquid (bovine serum). Figure 5a does not show the result for the coatings prepared with
( $\mathrm{Ar} / \mathrm{CH}_{4}$ ) flow of $210 / 10 \mathrm{sccm}$ due to the strong damage observed after a few cycles of test. In general, the COF values varied in the range of $0.10-0.18$ and $0.22-0.50$ for coatings produced with $\mathrm{Ar} / \mathrm{CH}_{4}$ flows of $190 / 30$ and $170 / 50 \mathrm{sccm}$, respectively. This variation could be associated to the hard debris interposed between the sliding surfaces ${ }^{33}$. Despite of having higher concentration of carbon in relation to titanium (see Figure 2), films deposited with $\mathrm{CH}_{4}$ flow of $50 \mathrm{sccm}$ showed higher COF values, which probably generated larger amount of wear debris.

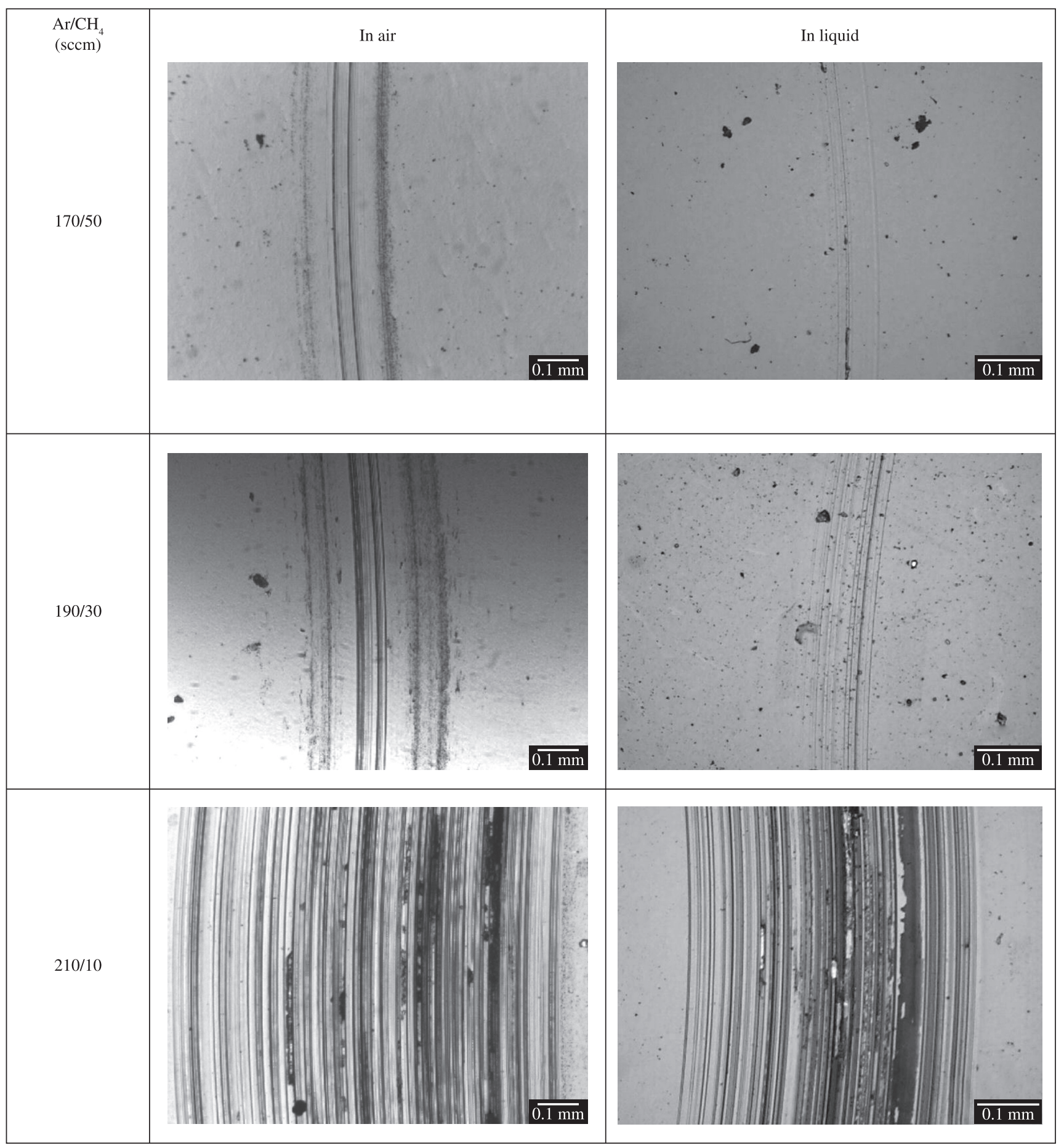

Figure 6. Optical micrographs of tracks formed on the coatings after 50,000 cycles for the tribological tests in air and in liquid (bovine serum). 
For tribological tests performed in bovine serum, the COF values appeared to increase up to 6,000 cycles, and then varied around an average value (Figure 5b). Also these values were higher compared to tests in air (Figure 5a). These findings were not expected once the bovine serum should act as a lubricant, decreasing the friction between the sliding surfaces as will be discussed hereafter.

Figure 6 shows the optical micrographs of typical tracks formed on the coatings submitted to tribological tests in air and in liquid. For tests in air, accumulation of wear debris along the tracks is observed on the samples. Further, the tracks become wider when the argon flow increases, that is, films prepared with lower methane flows are less wear-resistant. This could explain the substantially high COF obtained for the coatings deposited with $\mathrm{Ar} / \mathrm{CH}_{4}$ flows of 210/10 sccm, which were completely damaged. In all cases, the tracks formed on the coatings are narrower for tests in liquid compared to tests in air. This indicates that coatings were less damaged in tests in bovine serum, despite of having higher COF values in liquid (Figure 5). The proteins crystallization in bovine serum possibly influences the tribo-chemical reactions ${ }^{34}$, increasing the $\mathrm{COF}$ between the sliding surfaces. For the tribological parameters used here, the coatings deposited with $\mathrm{Ar} / \mathrm{CH}_{4}$ flows of 170/50 sccm are thus more wear-resistant.

Comparing the results for $E R$ from Tables 1 and 2 with the results from Figure 6, one can observe that those coatings with higher $E R$ values were less damaged. Therefore one could speculate that $E R$ and wear of the nanocomposite coatings are related, once high $E R$ values implies a more elastic material. But one must be careful of predicting wear by using the elastic recovery data, because the tribological system involves several important parameters that influence the final results, such as lubrication, environment, sliding surface pairs, load, velocity, etc.

Some works have pointed out that the presence of hard TiC crystals can improve the tribological properties of carbon-based films ${ }^{6-9}$. In fact, the arrangement and size of the TiC crystals, as well as the growth mode of the carbon films (columnar or compact, for instance) are responsible for the changes on the final properties of coatings. In our experiments, the presence of larger TiC nano-crystals did not seem to contribute to the wear resistance of coatings, as reported in the literature for TiC/a-C coatings ${ }^{9}$. The thicknesses of films about $300 \mathrm{~nm}$ possibly played an important role on the wear behaviour, once the applied hertzian contact pressure was considerably high. Hence a greater improvement of wear due to the presence of TiC crystals would be probably observed for thicker nanocomposite coatings. Even so, by taking into account the severe tribological conditions that they were submitted to, the nanocomposite coatings could be considered to tests on load bearing surfaces, such as hip joint simulator systems.

\section{Summary and Conclusions}

In this work, Ti-containing carbon coatings were prepared by reactive dc-magnetron sputtering. According to the $\left(\mathrm{Ar} / \mathrm{CH}_{4}\right)$ mass flows applied to deposition, the concentrations of $\mathrm{C}$ and $\mathrm{Ti}$ into nanocomposite coatings changed. For higher Ar flows, the concentration of $\mathrm{Ti}(\mathrm{C})$ raised (decreased) and the presence of nanometric-sized TiC crystals was observed. Hardness $(H)$ values were in the range of $8.8-15.9 \mathrm{GPa}$, and elastic modulus $(E)$ of 53.4 - $113.7 \mathrm{GPa}$ measured by nanoindentation tests. Higher $H$ and $E$ were obtained for nanocomposite films containing larger amount of TiC-phase. The presence of TiC crystals into carbon matrix increased the obtained coefficient of friction (COF) from 0.07 to 0.28 during scratch tests under low loads. All nanocomposite coatings had elastic recovery $(E R)$ of at least $75 \%$ for both nanoindentation and scratch tests. COF values obtained for wear tests in air varied in the range of $0.10-0.18$ and $0.22-0.50$ for films produced with $\mathrm{Ar} / \mathrm{CH}_{4}$ flows of 190/30 and 170/50 sccm, respectively. The deposited films presented higher COF values for wear tests in bovine serum, but the wear tracks were less marked in all cases. In addition, coatings with larger presence of TiC crystals had wider wear tracks formed on their surfaces. Notwithstanding, the produced TiC-doped carbon coatings could be tested as protective coatings on load bearing surfaces in aqueous medium.

\section{Acknowledgments}

Authors are grateful to the financial support from CNPq, CAPES and FAPERJ Brazilian funding agencies. Also thanks are due to Dr. D. Martínez-Martínez and Dr. O. Kubovà for their experimental helping.

\section{References}

1. Aisenberg $\mathrm{S}$ and Chabot R. Ion-beam deposition of thin films of diamondlike carbon. Journal of Applied Physics. 1971; 42(7):2953-2958.

2. Robertson J. Diamond-like amorphous carbon. Materials Science \& Engineering R-Reports. 2002; 37:129-281.

3. Damasceno JC and Camargo SS. DLC-SiOx nanocomposite films deposited from CH4:SiH4:O2 gas mixtures. Surface \& Coatings Technology. 2006; 200:6279-6282.

4. Hauert R and Muller U. An overview on tailored tribological and biological behavior of diamond-like carbon. Diamond and Related Materials. 2003; 12:171-177.

5. Musil J and Vlcek J. Magnetron sputtering of hard nanocomposite coatings and their properties. Surface \& Coatings Technology. 2001; 142:557-566.

6. Voevodin AA, Prasad SV and Zabinski JS. Nanocrystalline carbide amorphous carbon composites. Journal of Applied Physics.1997; $82: 855-858$

7. Voevodin AA and Zabinski JS. Load-adaptive crystalline-amorphous nanocomposites. Journal of Materials Science. 1998; 33(2):319-327.

8. Voevodin AA and Zabinski JS. Supertough wear-resistant coatings with 'chameleon' surface adaptation. Thin Solid Films. 2000; 370(1-2):223-231.

9. Martinez-Martinez D, Lopez-Cartes C, Fernandez A and Sánchez-López JC. Influence of microstructure on the mechanical and tribological behavior of TiC/a-C nanocomposite coatings. Thin Solid Films. 2009; 517:1662-1671.

10. Polcar T, Vitu T, Cvrcek L, Novak R, Vyskocil J and Cavaleiro A. Tribological behaviour of nanostructured Ti-C:H coatings for biomedical applications. Solid State Sciences. 2009;11:1757-1761.

11. Zehnder T, Schwaller P, Munnik F and Patscheider J. Nanostructural and mechanical properties of nanocomposite nc-TiC/a-C:H films deposited by unbalanced magnetron sputtering. Journal of Applied Physics. 2004; 95:4327-4334.

12. Zhang S, Bui XL, Jiang J and Xiaomin L. Microstructure and tribological properties of magnetron sputtered nc-TiC/a-C nanocomposite. Surface \& Coatings Technology. 2005; 198:206-211.

13. Hauert R. An overview in the tribological behavior of diamond-like carbon in technical and medical applications. Tribology International. 2004; 37:991-1003.

14. Shirakura A, Nakaya M, Koga Y, Kodama H, Hasebe T and Suzuki T. Diamond-like carbon films for PET bottles and medical applications. Thin solid Films. 2006; 494:84-91.

15. Casiraghi C, Robertson J and Ferrari AC. Diamond-like carbon for data and beer storage. Materials Today. 2007; 10:44-53.

16. Schmalzried TP and Callaghan JJ. Wear in total hip and knee replacements. Journal of Bone and Joint Surgery - Americam Volume. 1999; 81A:115-136.

17. Lappalainen R, Heinonen H, Anttila A and Santavirta S. Some relevant issues related to the use of amorphous diamond coatings for medical applications. Diamond and Related Materials. 1998; 7:482-485. 
18. Jin ZM, Stone M, Ingham E and Fisher J. Biotribology. Current Orthopaedics. 2006; 20:32-40.

19. Brizuela M, Garcia-Luis A, Viviente JL, Braceras I and Oñate JI. Tribological study of lubricious DLC biocompatible coatings. Journal of Materials Science - Materials in Medicine. 2002; 13:1129-1133.

20. Ahlroos T and Saikko V. Wear of prosthetic joint materials in various lubricants. Wear. 1997; 211:113-119.

21. Mckellop HA, Rostlund T, Ebramzadeh E and Sarmiento A. Wear of titanium 6-4 alloy in laboratory tests and in retrieved human joint replacements. In: Brunette DM, Tengvall P, Textor M and Thomsen P, editors. Titanium in Medicine. Berlin: Springer-Verlag; 2001.

22. Calonius $\mathrm{O}$ and Saikko V. Analysis of polyethylene particles produced in different wear conditions in vitro. Clinical Orthopaedics and Related Research. 2002; 399:219-230.

23. Andersson J, Erck RA and Erdemir A. Friction of diamond-like carbon films in different atmospheres. Wear. 2003; 254:1070-1075.

24. Lappalainen R, Anttila A and Heinonen H. Diamond coated total hip replacements. Clinical Orthopaedics and Related Research. 1998; 352:118-127.

25. Ahlroos T. Effect of lubricant on the wear of prosthetic joint materials. [PhD Thesis]. Finland: University of Helsinki; 2001. Available from: <http://lib.tkk.fi/Diss/2001/isbn9512258986>. Access in: 29 oct 2009.
26. Davis LE, Macdonald NC, Palmberg PW and Riach G. Handbook of Auger Electron Spectroscopy. $2^{\text {nd }}$ ed. USA: Physical Electronics Ind.; 1976.

27. Klug HP and Alexander LE. $X$-ray diffraction procedures. London: Wiley; 1988

28. Xu ZH and Rowcliffe D. Nanoindentation on diamond-like carbon and alumina coatings. Surface \& Coatings Technology. 2002; 161:44-51.

29. Oliver WC and Pharr GM. An improved technique for determining hardness and elastic-modulus using load and displacement sensing indentation experiments. Journal of Materials Research. 1992; 7:1564-1583.

30. Bhushan B. Modern Tribology Handbook. USA: CRC Press; 2001.

31. Long $M$ and Rack HJ. Titanium alloys in total joint replacement - a materials science perspective. Biomaterials. 1998; 19:1621-1639.

32. Voevodin AA, Capano MA, Laube SJP, Donley MS and Zabinski JS. Design of a Ti/TiC/DLC functionally gradient coating based on studies of structural transitions in Ti-C thin films. Thin Solid Films. 1997; 298:107-115

33. Guu YY, Lin JF and Ai CF. Correlation between three-body wear and tribological characteristics of titanium nitride, titanium carbonitride and titanium carbide coatings. Wear. 1997; 208:147-154.

34. Lappalainen R and Santavirta SS. Potential of coatings in total hip replacement. Clinical Orthopaedics and Related Research. 2005; 430:72-79. 